1 Universidade Anhanguera de São Paulo (Unian) - São Paulo (SP), Brasil. lucienejimenez@hotmail.com

2 Ministério do Planejamento, Orçamento e Gestão (MPOG) - Brasília (DF), Brasil. Ministério da Saúde (MS) - Brasília (DF), Brasil. danieladolpho@gmail.com

3 Universidade Anhanguera de São Paulo (Unian) - São Paulo (SP), Brasil. Escola Estadual Fábio Eduardo Ramos Esquível - Diadema (SP), Brasil.

ronaldo.gn@gmail.com

\section{Direitos sexuais e reprodutivos de crianças e adolescentes: desafios para as políticas de saúde}

\author{
Sexual and reproductive rights of children and adolescents: challenges \\ for health policies
}

Luciene Jimenez', Daniel Adolpho Daltin Assis², Ronaldo Gomes Neves ${ }^{\mathbf{3}}$

RESUMO Pesquisa qualitativa documental que analisou - a partir da compreensão de paradigma proposta por Kuhn - como a saúde e os direitos sexuais e reprodutivos estão previstos nas normas e leis brasileiras que regulam os direitos de crianças e adolescentes, incluindo aqueles que se encontram em conflito com a lei. Os paradigmas contraditórios, a questão do 'consentimento’ e as violências acenam como desafios para a execução das políticas de saúde. Como estratégia, propõe-se o exercício de tais direitos com diretriz ética enquanto 'o cuidado de si', conforme compreendido por Foucault. Atenta-se, ainda, para o princípio da incompletude institucional como égide para tal transformação.

PALAVRAS-CHAVE Direitos sexuais e reprodutivos; Saúde do adolescente; Políticas públicas; Legislação como assunto.

ABSTRACT Documental qualitative research that analyzed - from the comprehension of paradigm according to Kuhn's proposal - how health and the sexual and reproductive rights are foreseen in Brazilian norms and laws that regulate children and adolescent rights, including those that are in conflict with the law. The contradictory paradigms, the issue of 'consent' and violence stand out as challenges for the execution of health policies. As a strategy, it is proposed that the exercise of those rights with an ethical parameter as 'care of the self', as comprehended by Foucault. Furthermore, attention should be paid to the principle of institutional incompleteness as foundation for such transformation.

KEYWORDS Sexual and reproductive rights; Adolescent health; Public policies; Legislation as topic. 


\section{Introdução}

Os direitos sexuais e reprodutivos de crianças e adolescentes são amplamente reconhecidos, como será visto adiante, por meio de Conferências Internacionais das quais o Brasil é signatário. Apesar disso, a temática é complexa e contraditória. A própria noção de infância/adolescência é uma construção social e cultural que pode variar grandemente no tempo histórico ou entre as culturas, podendo variar também a partir de fatores, como a classe social. Os limites convencionados social e culturalmente para delimitar as fases da vida vão incidir no momento considerado adequado para a criança receber as informações sobre sexualidade e reprodução, bem como para a anuência ou não da prática sexual.

Melo (2010) considera que falar de direito, sexualidade e infância/adolescência em uma perspectiva emancipatória é tarefa no mínimo espinhosa, seja pelas reações que o tema suscita, seja pelas parcas reflexões teóricas. $\mathrm{O}$ mesmo autor aponta que o número de meninas brasileiras entre 10 e 14 anos que deram à luz em hospitais públicos passou de 24,8 mil em 2005 para 26,3 mil em 2007, evidenciando a importância de enfrentar o tema e seus espinhos.

Não obstante, ao se incluir na temática os e as adolescentes que se encontram em cumprimento de medida socioeducativa, o desafio é redobrado. $\mathrm{O}$ termo 'adolescentes em cumprimento de medida socioeducativa' remete a um grupo de jovens entre 12 e 21 anos incompletos de idade que foram responsabilizados judicialmente por ato infracional ocorrido no decorrer da adolescência (entre 12 e 18 anos incompletos) devido à prática de conduta descrita em lei como crime ou contravenção penal. Tal responsabilização implica o cumprimento de medida socioeducativa, sendo seis as modalidades possíveis: duas de privação/ restrição de liberdade (a internação e a semiliberdade); duas exauridas no âmbito do judiciário (a advertência e a obrigação de reparar o dano); as outras duas executadas em meio aberto (a Prestação de Serviços à Comunidade - PSC - e a Liberdade Assistida - LA) (BRASIL, 1990).

Dados do ano de 2012 indicam um número de 20.532 adolescentes em restrição e privação de liberdade (internação, internação provisória e semiliberdade), e de $88.022 \mathrm{em}$ meio aberto (prestação de serviços à comunidade e liberdade assistida), totalizando 108.554 adolescentes em cumprimento de alguma medida socioeducativa. Tais números representam $0,51 \%$ da população total de adolescentes (BRASIL, 2014B).

No cenário nacional, observa-se que $95 \%$ são do sexo masculino, egressos do sistema formal de ensino, vivendo nas regiões mais pauperizadas e com acesso restrito aos direitos básicos. Embora sejam escassos os estudos sobre direitos e saúde sexual e reprodutiva desse grupo, pode-se inferir que se trata de um grupo com menor acesso também a essa dimensão da saúde. Assis e Souza (1999), ao entrevistarem adolescentes infratores e seus irmãos ou primos não infratores, identificaram que:

Todos os infratores entrevistados relataram ter ou já terem tido namorada, sendo que cinco deles já viviam com suas mulheres. Alguns revelaram ter começado a namorar muito precocemente, por volta dos oito anos de idade e iniciado a vida sexual entre os dez e treze anos. A relação com as namoradas é efêmera e o relato de ocorrência de gravidez foi muito comum. A maioria das garotas não chegou a ter o filho, mostrando a frequência com que o aborto é feito por esse grupo social. $\mathrm{O}$ número elevado de gravidez das namoradas e o de filhos nascidos evidencia, de um lado, a pouca utilização de métodos para evitar a concepção e, de outro, a ausência de medidas preventivas relacionadas a doenças sexualmente transmissíveis. [...] Os irmãos/primos entrevistados têm o mesmo comportamento no que se refere à alta rotatividade nos relacionamentos e envolvimentos paralelos. Entretanto, tiveram uma entrada na 
vida sexual mais tardia e apresentaram maior preocupação com a prevenção de gravidez e doenças, embora tal comportamento nem sempre se expressasse em medidas eficazes. Nesse grupo, foram poucos os relatos de interrupção de gravidez; foi maior o número de jovens que assumiram a paternidade e que planejaram com cautela a futura constituição de suas vidas conjugais. (ASSIS; SOUZA, 1999, P. 140).

No que diz respeito às adolescentes que se encontram em cumprimento de medida socioeducativa, Dell'Aglio et al. (2005) identificaram importantes eventos estressores vivenciados na esfera da sexualidade, tais como: 'ficar grávida', 'ser estuprada', 'ser tocada sexualmente contra a vontade' e 'fazer aborto'. Os adolescentes e jovens constituem um grupo populacional que necessita de novos modos de produzir saúde, em particular, a saúde sexual e reprodutiva (PASCHE ET AL., 2014), e tal afirmação deve incluir aqueles que estão em conflito com a lei.

Nesse sentido, cabe realizar um sucinto resgate histórico sobre a constituição semântica do campo da saúde e dos direitos sexuais e reprodutivos, com ênfase na infância/adolescência.

\section{Saúde sexual e reprodutiva}

As questões e discussões referentes ao exercício da sexualidade e da reprodução humana atravessaram todo o século XX com marcos internacionais importantes, entre eles, as três Conferências Internacionais da Mulher (MÉXICO, 1975, COPENHAGUE, 1980, NAIRÓBI, 1985). A Conferência Internacional sobre População e Desenvolvimento, no Cairo, em 1994, pautou os direitos reprodutivos, incluindo os adolescentes e atentando no item 'e' do capítulo VII para o fato de que, enquanto grupo, os adolescentes são particularmente vulneráveis e ignorados pelos serviços de saúde reprodutiva.

No ano seguinte, a IV Conferência Mundial sobre a Mulher, em Pequim (1995), retomou a relação entre direitos e sexualidade, porém enquanto as diretrizes do Cairo enfatizaram o direito à reprodução, foi com o evento de Pequim que a sexualidade assumiu relevância ao propor o respeito com as diferentes expressões sexuais que fogem ao tradicional binômio normativo masculino/feminino; ou seja, homossexuais, transexuais, travestis e transgêneros passaram a ter seus direitos reconhecidos nas diretrizes de Pequim (VENTURA ET AL., 2003, P. 35).

Em 1999, a Organização das Nações Unidas (ONU) realizou um processo de revisão e avaliação da implementação dos direitos sexuais e reprodutivos conquistados até então - Cairo + 5 -, avançando, entre outros tópicos, nos direitos dos adolescentes. De acordo com Ventura (2005, P. 37),

Na revisão do documento, deixou de ser incluído o direito dos pais em todas as referências aos adolescentes, garantindo o direito dos adolescentes à privacidade, ao sigilo, ao consentimento informado, à educação, inclusive sexual no currículo escolar, à informação e à assistência à saúde sexual e reprodutiva.

Pode-se afirmar que os direitos sexuais e reprodutivos de crianças e adolescentes são amplamente reconhecidos no cenário internacional e supostamente no nacional, uma vez que o Brasil foi signatário dos documentos resultantes de tais eventos.

Nesse sentido, foram objetivos deste trabalho identificar como tais direitos estão sendo contemplados nas leis e normas nacionais que organizam os direitos de crianças e adolescentes - inclusive daqueles que se encontram em conflito com a lei -, para, a seguir, sem a intenção de esgotar o tema, traçar alguns desafios para a execução das políticas de saúde.

\section{Método}

Trata-se de uma pesquisa qualitativa documental que teve como objetivo analisar dois 
documentos e duas leis nacionais que remetem aos direitos das crianças e adolescentes e propõem a organização do funcionamento do sistema socioeducativo brasileiro. A pesquisa qualitativa é aquela que busca incorporar a intencionalidade, os significados, afetos e outras dimensões subjetivas da vida (MINAYO, 1992). Quanto à pesquisa documental, Gil (1994) refere que os conteúdos dos textos tiveram pouco tratamento analítico, constituindo assim material a partir do qual o pesquisador pode desenvolver sua investigação e análise.

As normas analisadas foram: 1) Lei Federal 8.069/1990 - Estatuto da Criança e do Adolescente (ECA); 2) Lei 12.594/2012. E os documentos: 1) Resolução do Conselho Nacional dos Direitos da Criança e do Adolescente (Conanda) n. ${ }^{\circ}$ 119/2006 Sinase; 2) Portaria Interministerial n. ${ }^{\circ}$ 647, de 11 de novembro de 2008.

A análise buscou identificar a presença dos paradigmas que organizam a concepção de saúde e direitos sexuais na infância e adolescência. A compreensão de paradigma é utilizada para estabelecer diferenças entre dois momentos ou dois níveis do processo de conhecimento científico (KUHN, 1989). Pode-se compreender o paradigma como um modelo de ciência que serve como referencial para o fazer científico de determinada época. Tal modelo tende a se esgotar, sendo suplantado por outro, cujas bases estruturantes sugerem maior confiabilidade. Pode ocorrer de dois ou mais paradigmas se superporem ou disputarem espaços de hegemonia na construção do conhecimento científico. Para tanto, foi realizada uma combinação entre critérios cronológico e hierárquico: partindo da primeira lei - ECA, 1990; em seguida, a Portaria Interministerial n. ${ }^{\circ}$ 647/2008; a Resolução n. ${ }^{\circ} 119$, de 2006 (BRASIL, 2006), e, por fim, a Lei 12.594 de 2012, a fim de observar como o tema estudado foi abordado no decorrer do tempo, quais as expressões utilizadas para fazer menção aos direitos ou saúde sexual/reprodutiva, sexualidade e qual a abrangência do capítulo, eixo ou parágrafo no qual tais termos estavam inseridos.

\section{Discussão}

\section{ECA - Lei Federal 8.069/1990: para- digma da sexualidade como violência}

O ECA foi a primeira lei a ser analisada, pois representa uma evolução sem precedentes ao propor a criança e o adolescente como sujeitos de direitos, superando a compreensão tutelar da Doutrina da Situação Irregular, preconizada pelo Código de Menores de 1979, que os tratava como objetos de intervenção estatal.

Embora o ECA tenha gerado uma compreensão integral, na perspectiva dos direitos e não do dever do Estado em intervir na vida dessa população -, o campo temático aqui tratado ainda não é alvo pleno dessa nova leitura que inclui os direitos sexuais e reprodutivos na agenda política atual dos direitos humanos. Predomina a compreensão negativa da sexualidade, ou seja, aquela segundo a qual crianças e adolescentes devem ser protegidos de possíveis violências, abusos e exploração sexual.

Os verbos utilizados remetem sistematicamente ao ato de proteger a criança e o adolescente da possibilidade de ser tratado como um objeto sexual, a sexualidade é contextualizada como 'crime', sendo o adulto envolvido apresentado enquanto 'agressor'. Nas palavras de Pirotta e Pirotta (2005, P. 88),

\section{O tratamento que o ECA dá aos direitos sexu- ais e reprodutivos de crianças e adolescentes é sempre pela negativa, ou seja, tem sempre o intuito de prevenir o abuso e a exploração sexual de crianças e adolescentes pelos adul- tos. É notável a ausência de direitos afirma- tivos referentes à vida sexual e reprodutiva.}

No entanto, para Ventura et al. (2003), algumas garantias previstas no ECA criam pressupostos fundamentais para que os direitos sexuais e reprodutivos sejam assegurados na assistência à saúde, tais como: 1 - O reconhecimento de adolescentes como sujeitos de 
direitos implica a garantia da privacidade, do sigilo e no consentimento informado; 2 - A garantia do direito ao respeito, como inviolabilidade da integridade física, psíquica e moral desses sujeitos, e preservação da imagem, identidade, da autonomia, dos valores, das ideias e crenças, da opinião e expressão, dos espaços e objetos pessoais; 3 - A afirmação da natureza tutelar do direito à saúde, isto é, sua definição como um direito cuja garantia exclui qualquer outra norma que prejudique o bem tutelado, neste caso, a saúde.

Ainda para Ventura et al. (2003), em relação aos adolescentes em situação de privação de liberdade, o Estatuto estabeleceu, no seu artigo 124, uma série de garantias, denominadas como 'rol de direitos fundamentais', e adotou a expressão 'dentre outros', indicativa de que o rol ali apresentado não está esgotado, o que significa dizer que, além desses direitos básicos e fundamentais, podem e devem ser garantidos outros, abrindo possibilidade para a inclusão dos sexuais e reprodutivos.

Dessa forma, embora o ECA não trate de direitos sexuais e reprodutivos na adolescência nem mesmo reconheça a existência da sexualidade para esse grupo, no seu âmbito geral, busca proteger crianças e adolescentes de possíveis violências de natureza sexual. Ao mesmo tempo, ao propor o amplo acolhimento em saúde, deixa em aberto possibilidades para a ampliação de interpretação e ação que possam reconhecer direitos conquistados posteriormente.

\section{Portaria Interministerial $n$. ㅇ 647/2008: o paradigma biológico e normatizador da sexualidade}

Existem três Portarias Interministeriais referentes à saúde de adolescentes em situação de privação de liberdade: a Portaria n. ${ }^{\circ} 1.426 / 2004$ (BRASIL, 2004A), que aprovou as diretrizes para a implantação e implementação da atenção à saúde dos adolescentes em conflito com a lei, em regime de internação e internação provisória; a Portaria SAS/MS n.ำ
340/2004 (BRASIL, 2004B), que ampliou e detalhou as propostas, delineando-as nas formas de anexos operativos e técnicos, sendo revogada pela Portaria SAS/MS n. 647/2008 (BRASIL, 2008), que, em linhas gerais, mantém as determinações veiculadas na anterior e por isso será foco de análise.

No item 4.3.2, a Portaria 647/2008 (BRASIL, 2008) estabeleceu, sob o título 'Saúde sexual e saúde reprodutiva', as ações direcionadas para ambos os sexos e as ações voltadas ao sexo feminino, não havendo ações específicas para o sexo masculino, bem como reduzindo o recorte de gênero apenas ao binômio hegemônico. As ações a serem desenvolvidas foram compreendidas como práticas educativas e versaram sobre a dimensão orgânica, tais como: contracepção, controle do câncer uterino, autoexame da mama, contracepção, pré-natal, prevenção e tratamento sindrômico das Doenças Sexualmente Transmissíveis (DST), tratamento do vírus da imunodeficiência humana (HIV). No item 4.3.2.2, letra 'G', propõe 'Proporcionar ambiente e condições favoráveis para aleitamento materno', porém não estipula tempo mínimo para a permanência do bebê com a mãe, o que é genericamente garantido apenas no art. $63 \subseteq 2^{\circ}$ da Lei 12.594/12 (BRASIL, 2012).

No que diz respeito aos direitos sexuais e reprodutivos dos e das adolescentes em privação de liberdade, o documento mantém-se superficial sobre os procedimentos incluídos nas ações socioeducativas, demonstrando seu alcance, no máximo, sobre as atividades referentes à 'violência doméstica e social' e 'violência e abuso sexual', ambas com recorte no gênero feminino (BRASIL, 2008).

É indiscutível o avanço da proposta, no entanto, a Portaria reduz os direitos sexuais e reprodutivos ao binômio normativo masculino/feminino, atentando para a dimensão biológica e patognomônica da sexualidade e silenciando sobre as demais expressões de sexualidade, como a presença, nas unidades de internação, de adolescentes homossexuais, transgêneros ou intersex. 
O caráter médico/sanitário atribuído à atividade sexual talvez tenha sido motivado pelo momento em que foi escrita a Portaria, pois coincide com o avanço das doenças sexualmente transmissíveis entre adolescentes, em particular pela epidemia da Aids, fato que despertava grande preocupação por parte da população e das autoridades, fazendo com que pairasse sobre o sexo o perigo da 'peste', do adoecimento e da morte.

\section{Resolução $\mathrm{n}$. 9119 do Conanda de 2006 (Sinase): as dimensões afetiva e política da sexualidade}

Em fevereiro de 2004, a então Secretaria Especial dos Direitos Humanos (Sedh), por meio da Subsecretaria de Promoção dos Direitos da Criança e do Adolescente (SPDCA), em conjunto com o Conanda e com o apoio do Fundo das Nações Unidas para a Infância (Unicef), sistematizou e organizou a proposta do Sistema Nacional de Atendimento Socioeducativo (Sinase) (BRASIL, 2006). Tornado Resolução, o documento não ganhou, então, força de lei, mas adquiriu legitimidade por ser tanto deliberação de Conselho de Estado quanto resultado de uma construção coletiva e de um processo democrático e estratégico.

Mais amplo do que o normativo analisado anteriormente, o Sinase atém-se ainda menos, especificamente, à saúde sexual e reprodutiva, mas apresenta como grande inovação com relação aos documentos anteriores a expressão 'orientação sexual' e a trata juntamente com a diversidade étnico-racial e de gênero. Não obstante, no capítulo 6, apresenta as referidas temáticas enquanto norteadoras da prática pedagógica,

Questões da diversidade cultural, da igualdade étnico-racial, de gênero, de orientação sexual deverão compor os fundamentos teórico-metodológicos do projeto pedagógico [...]; sendo necessário discutir, conceituar e desenvolver metodologias que promovam a inclusão desses temas, interligando-os às ações de promoção de saúde, educação, cultura, profissionalização e cidadania [...], possibilitando práticas mais tolerantes e inclusivas. (BRASIL, 2006, p. 49).

Aspecto reforçado no eixo 6.3.2, onde inclui também a questão da identidade. "Diversidade Étnico Racial, gênero e orientação sexual, que sejam realizadas ações que abordem as três dimensões em questão, bem como, o tema da identidade" (BRASIL, 2006, P. 58).

Um segundo elemento assume relevância: a emergência da expressão 'direito sexual' não restringindo a temática à saúde sexual e, ao mesmo tempo, explicitando que as ações devem ser desenvolvidas em parcerias com as secretarias de saúde municipais.

Eixo 6.3.5 - [...] 3) oferecer grupos de promoção de saúde incluindo temas relacionados à sexualidade e 'direitos sexuais', prevenção de DST/Aids, uso de álcool e outras drogas, orientando o adolescente, encaminhando-o e apoiando-o, sempre que necessário, para o serviço básico de atenção à saúde; 4) buscar articulação e parcerias com a Secretaria de Saúde do Município a fim de receber apoio e desenvolver programas [...]. (BRASIL, 2006, p. 60, destaque nosso).

A possibilidade de visita íntima foi afirmada no item 6.2.1, que tratou da distribuição dos diferentes espaços, prevendo espaço e condições adequadas para visita íntima, o que foi confirmado posteriormente na Lei.$^{\circ}$ 12.594/12.

O documento inova quanto à compreensão do exercício da sexualidade para além da proteção da saúde, pois, como direito, insere a temática no eixo político-pedagógico juntamente com outras dimensões do desenvolvimento, como etnia e gênero, reconhecendo a sexualidade como dimensão afetiva e, ao mesmo tempo, política para a existência humana. Reflete bem a sexualidade compreendida não apenas como instância da vida íntima ou privada, mas também 
como exercício político, público, arena de disputas e constituição de subjetividades (FOUCAULT, 1988).

\section{Lei 12.594/12, de 18 de janeiro de 2012: o retorno ao paradigma biológico}

A Lei $12.594 / 12$ foi sancionada seis anos após a publicação do Sinase com o objetivo de dar a este documento o estatuto legal. No entanto, enquanto o primeiro documento avança, entre as 122 páginas, sobre conceitos, estratégias e procedimentos de garantia de direitos nos quais são detalhados os princípios e ações, as breves 24 páginas da lei se dividem entre inovar na inscrição de procedimentos de gestão e reiterar a maioria dos direitos já assegurados no ECA - elidindo a expressão ‘direitos sexuais' presente na Portaria anterior.

A primeira menção a questões de sexualidade se dá no Título II - Da Execução das Medidas Socioeducativas - Capítulo I, Disposições Gerais, $\subseteq 8^{\circ}$, que aborda a não discriminação, incluindo gênero e orientação sexual, como um dos princípios a regerem a execução das medidas (BRASIL, 2012A).

A seguir, a saúde integral é reconhecida como um direito individual no Capítulo III, e o art. 60, inciso IV, trata pontualmente da saúde sexual e reprodutiva, informando que a atenção integral seguirá, entre outras diretrizes, a "disponibilização de ações de atenção à saúde sexual e reprodutiva e à prevenção de doenças sexualmente transmissíveis" (BRASIL, 2012A). Ou seja, a temática até então presente no eixo político-pedagógico da Resolução n. ${ }^{\circ} 119$ do Conanda (BRASIL, 2006) retorna para o eixo da saúde.

A visita íntima para adolescentes que se encontram internados(as) consta entre as especificações de visitas e é contemplada no art. 68:

É assegurado ao adolescente casado ou que viva, comprovadamente, em união estável o direito à visita íntima.Parágrafo único. O visitante será identificado e registrado pela direção do programa de atendimento, que emitirá documento de identificação, pessoal e intransferível, específico para a realização da visita íntima. (BRASIL, 2012a).

O fato de a visita íntima ter sido contemplada manteve a conquista já estabelecida no documento de 2006, no entanto, as restrições colocadas, como comprovação de união estável, podem criar limitações ao exercício do direito para parte expressiva dos e das adolescentes. Ademais, não basta identificar o complicador de ordem cartorial, pois a relação pode até se dar sob a insígnia da união estável, porém de modo informal, como ocorre com significativa parte da população brasileira, ainda mais na adolescência. Trata-se, ainda, de condicionar o exercício dos direitos sexuais a um estado civil, negando-se, portanto, todas as demais dimensões desse direito consagradas na legislação internacional e nacional durante as décadas anteriores.

Orientação sexual e gênero deixaram de fazer parte da política de atenção à saúde e passam a constar exclusivamente no parágrafo que visa a não discriminação. Em suma, a lei empalideceu várias conquistas presentes no documento inicial datado de 2006, fazendo com que uma parcela importante de adolescentes privados de liberdade siga também privada do exercício de seus direitos sexuais e reprodutivos. À revelia da realidade brasileira, a principal norma inovadora no tema - visita íntima - não apenas apresenta baixo impacto (pois é restrita à condição de união civil) como também cerceia absolutamente o exercício que não seja heteroafetivo e para maiores de 16 anos de idade. Em suma, a lei sugere um retorno ao paradigma organicista.

\section{Desafios para as políticas públicas}

Um primeiro desafio está colocado na presença de diferentes paradigmas que 
legitimam o acesso à saúde sexual e reprodutiva de crianças e adolescentes, fazendo com que tais concepções se reflitam no dia a dia de profissionais e gestores. Transcender a lógica exclusiva da proibição e da censura, sem abdicar da real necessidade de sua observância e, ao mesmo tempo, inserir a sexualidade na infância/adolescência enquanto instância constitutiva dos afetos, das identidades, da noção de quem se é, enfim, das dimensões da subjetividade, constitui um primeiro desafio para as políticas de saúde.

Avaliando que os direitos sexuais e reprodutivos devem ser tratados "no sentido libertário e igualitário, e não no sentido prescritivo de constituição de um modelo e regras para o exercício da sexualidade e da vida reprodutiva" (ÁVILA, 2003, P. 466), elencaram-se mais dois desafios que, embora não estejam explicitados nas normas e leis analisadas, fazem-se presentes no Código Penal e no cotidiano dos adolescentes em cumprimento de medida socioeducativa em instituições fechadas: a questão do 'consentimento' e as situações de violência sexual.

\section{A criança/adolescente como sujeito de direitos: a lei do 'estupro presumi- do' e a questão do 'consentimento'}

O artigo 224 do Código Penal brasileiro presume a existência de violência - estupro - em qualquer relação sexual com adolescente do sexo feminino ou masculino menor de 14 anos de idade. Esse artigo impacta diretamente nas discussões e na execução das políticas de saúde sexual e reprodutiva de crianças e adolescentes, levando a questionar a partir de qual idade uma pessoa tem o reconhecimento de autonomia para consentir, de maneira considerada válida, uma relação sexual.

Laura Lowenkron (2007, P. 735) propõe que "a noção de consentimento pode ser definida como uma decisão de concordância voluntária tomada por um sujeito dotado de capacidade de agência e livre-arbítrio", e realiza uma reflexão sobre a "menoridade sexual' por meio da análise de um julgamento de um jovem de 24 anos que manteve relações sexuais com uma adolescente de 12 anos. Alguns dos argumentos apresentados pelos ministros participantes do julgamento versaram sobre os seguintes fatos: o rapaz não poderia prever a menoridade, pois a adolescente aparentava ter 15 anos; a adolescente era precoce mentalmente e promíscua sexualmente; as carícias trocadas antes do ato sexual representariam ou não constrangimento? Afinal, como identificar se houve ou não consentimento de fato, apesar de a adolescente afirmar que 'transou porque pintou vontade'?

É possível observar nos argumentos dos ministros a presença de uma determinada compreensão do desenvolvimento humano na qual as características biológicas da puberdade tendem a se superpor à maturação afetiva e moral. Ou seja, uma vez tendo aparência de 15 anos, a adolescente teria maturidade equivalente. Por outro lado, independentemente da aparência, alguns ministros consideraram os adolescentes "como indivíduos incompletos e de personalidade indefinida, ou seja, não tendo desenvolvido ainda a capacidade de autocontrole de seus instintos, portanto considerados incapazes para o exercício pleno da liberdade sexual" (LOWENKRON, 2007, P. 731). Ambas as compreensões partem do paradigma biologicista da sexualidade humana que pouco considera a subjetividade e, portanto, cria importantes limites para discutir o consentimento.

Em contrapartida a essas concepções e como forma de garantir a condição de sujeito de direitos de crianças e adolescentes, propõe-se o desafio de um paradigma de desenvolvimento que se faz de modo heterogêneo, ou seja, levando em consideração as particularidades entre os indivíduos, e sem que as diferentes instâncias (física, intelectual, 
sexual, moral etc.) se superponham, mas, antes, dialoguem entre si.

Para além do desenvolvimento perceptível e sensível para com o corpo, faz-se necessário o desenvolvimento de uma cultura da ética do sujeito. Uma ética que promova junto aos indivíduos condições para desenvolver a capacidade de manejar, por recursos próprios, um número de operações sobre seu corpo, pensamentos e condutas, de tal modo que possa transformar a si mesmo e ao mundo que o cerca (FRANÇA, 1996).

Nesse caminho, é necessário desvincular o discurso normativo e tutelar a respeito de crianças/adolescentes para compreendê-los a partir de suas próprias vozes e interesses, promovendo o desejo e o exercício do assenhoramento de si mesmo e de suas práticas. Ou seja, não é apenas se questionar 'eu quero transar? Eu posso transar?' E a lei irá responder: 'Hoje não, mas amanhã, com 14 anos de idade, sim'. Ao contrário, desdobrar a questão em pauta para promover a apreensão do desejo sexual e sua implicação com a vida e com sua condição de sujeito. 'Eu quero transar com essa pessoa? Essa pessoa quer transar comigo? Quais as consequências que podem advir? Estamos preparados para as consequências? Como nos preparar?' Propõe-se, portanto, a promoção de uma cultura que compreenda o exercício sexual enquanto parte da saúde sexual como um exercício ético de poder sobre si mesmo e sobre o seu corpo voltado para a conquista da autonomia, e não como uma prática de impulsos a serem controlados ou liberados em determinados tempos e momentos ditados pelo contexto exterior.

O exemplo apresentado por Lowenkron (2007), no qual a adolescente relata que transou porque 'pintou vontade', exemplifica bem o que está se chamando aqui de 'prática dos impulsos', realidade extensiva a muitos outros adolescentes, uma vez que é essa a reserva de conhecimentos e autonomia que a sociedade lhes oferece para lidar com a sexualidade.
Como instrumento para oportunizar tal giro paradigmático que vai da 'prática dos impulsos' para a 'autonomia sobre si mesmo', propõe-se o conceito de 'cuidado de si', conforme compreendido por Foucault (2010) e seus leitores que, sinteticamente, implicaria:

1) Romper com a mentalidade tutelar, ainda presente em parte da legislação analisada e cujos ecos se fazem presentes nos discursos dos profissionais de saúde, apostando no entendimento que tal população pode, livremente, assumir sua própria constituição de sujeito. Para tal, devem ser ouvidos e motivados a olharem para si com uma atitude investigativa de como se tornaram o que são, de como o mundo no qual estão imersos procurou produzir suas subjetividades (CAVALCANTE JUNIOR, 2008).

2) Desenvolver estratégias não como normas universais às quais todos devem se submeter, mas como princípios de estilização da conduta proposto àqueles que queiram dar à sua existência a forma mais bela, mais justa e mais realizada possível (FOUCAULT, 1984).

Tais desafios provocam o desenvolvimento criativo de espaços de fala e escuta, de técnicas que permitam a crianças e adolescentes expressarem suas percepções sobre seus corpos e desejos antes de agirem, tendo como objetivo alcançar o governo de si como expressão de liberdade e de autonomia.

Não se trata de uma solução mágica, pois está claro que para levar a cabo tal desafio se deve ousar romper com o silencio que ainda paira sobre o sexo e as sensibilidades a ele associadas, mantendo-o como um tabu que atravessa os séculos. Não se pretende esgotar o tema, tampouco responder a questões, por exemplo: como conversar com crianças de diferentes idades, incluindo as de idade pré-escolar, sobre as sensibilidades de seus corpos ou sobre como os bebes são feitos. Ao invés disso, apenas afirmar que crianças e adolescentes podem falar sobre tais questões caso haja quem 
os escute, e tal fato pode ser efetivo para a construção desse grupo como sujeitos, possibilitando não apenas o exercício ético da sexualidade, mas também contribuindo para protegê-los das situações de violência e abuso, bem como das doenças e gravidez indesejada, focos de preocupação de diversas leis e normas aqui analisadas.

\section{Algumas particularidades de adoles- centes que se encontram em cumpri- mento de medida socioeducativa de internação}

Existem importantes questões que compõem os direitos sexuais e reprodutivos e fazem parte do cotidiano dos adolescentes que se encontram no sistema socioeducativo, principalmente daqueles que se encontram em privação de liberdade, e não se restringem às doenças ou gravidez indesejada. As violências que acontecem dentro das unidades de internação, incluindo a violência sexual e de gênero, o preconceito e a discriminação contra as diferentes expressões de sexualidade, fazem-se presentes no cotidiano desses adolescentes e não foram evidenciadas nas leis e normas analisadas. Uma pesquisa realizada pelo Conselho Nacional de Justiça entre os anos 2010 e 2011 em 320 estabelecimentos de internação identificou que:

Dos dados, destaca-se o número de estabelecimentos que registraram situações de abuso sexual sofrido pelos internos: em 34 estabelecimentos pelo menos um adolescente foi abusado sexualmente nos últimos 12 meses. Em 19 estabelecimentos há registros de mortes de adolescentes em cumprimento de medidas socioeducativas. [...] e dois registraram mortes por suicídio nos últimos 12 meses. A violência sofrida por adolescentes no interior dos estabelecimentos enseja mais atenção do Estado. (BRASIL, 2012B, P. 127).

Os dados acima explicitam o paradigma da sexualidade como expressão da violência, escopo de preocupação do ECA. É possível que a efetivação real da visita íntima prevista no Sinase (BRASIL, 2006), enquanto parte do eixo político-pedagógico, não só abrandasse tais eventos como também pudesse abrir novas possibilidades para promover aos e as adolescentes a compreensão de sexualidade enquanto governo de si, e não enquanto 'prática dos impulsos' e/ou opressão e domínio do outro.

Não obstante, a ansiada maior atenção do Estado à qual o documento se refere implica, entre outras ações, acionar o princípio da Incompletude Institucional que rege o Sistema de Garantia de Direitos de Crianças e Adolescentes. A Incompletude Institucional propõe um conjunto articulado de ações governamentais e não governamentais, de base territorial, institucional e comunitária para a organização das políticas de atenção à infância e à adolescência (BRASIL, 2006). Partindo desse princípio, ações de saúde devem ser realizadas em cooperação com serviços dos três níveis de atenção, sobretudo as Unidades Básicas de Saúde e os Centros de Referência em DST/Aids responsáveis pelo território no qual se localiza a Unidade de Internação.

Nesse sentido, uma larga avenida a se atravessar pode ser a encontrada na Portaria GM/MS n. ${ }^{\circ}$ 1.082/2014, 'Política Nacional de Atenção Integral à Saúde de Adolescentes em Conflito com a Lei, em Regime de Internação e Internação Provisória (PNAISARI)'. A PNAISARI apresenta uma importante novidade: realizar ações de matriciamento no processo saúde-doença-cuidado em construção entre técnicos do sistema socioeducativo e adolescentes internados/as, não sendo a principal atividade "o atendimento individual, ambulatorial, nem mesmo a realização de avaliações demandadas pelo Judiciário" (BRASIL, 2014A). Essa modalidade de gestão compartilhada entre socioeducativo e saúde ocorre "em virtude da importância da promoção de saúde mental em instituições fechadas, do reconhecimento do sofrimento psíquico decorrente da institucionalização" (BRASIL, 2014A). Considerando que a atenção psicossocial seja 
uma importante dimensão da saúde sexual e reprodutiva, e enquanto os direitos referentes a esses estejam arriscadamente assentados pela atual Lei n. ${ }^{\circ} 12.594 / 2012$, no direito à saúde, um significativo lastro estratégico pode ser a PNAISARI, porquanto deve arrancar das ruas e das redes de atenção - logo, fora da instituição total -, por meio de ações de matriciamento, as atividades de promoção de saúde, especialmente pela necessária aproximação dos profissionais das unidades básicas de saúde e, no caso em tela, dos Centros de Referência em DST/Aids. A nova força centrífuga presente nas ações de cuidado pode significar um passo na consolidação do princípio da incompletude institucional, bem como, consequentemente, um percurso de afirmação ética avesso à instituição total e, logo, justificador de uma discursividade validadora das liberdades, inclusive de pensamento, desejos e participação.

\section{Considerações finais}

Ao se analisar as leis e normas em questão, têm-se consciência da expressiva contribuição que cada uma delas representa, já que:

a regulamentação [de tais documentos] aconteceu dentro do contexto da Constituição Federal de 1988, que promoveu o reordenamento jurídico brasileiro pondo fim ao período de
Ditadura Militar, e onde a afirmação dos direitos dos cidadãos foi a tônica fundamental. (NEVES, 2015, P. 93).

Ainda que os paradigmas se apresentem contraditórios entre si, tal fato reflete as diferentes compreensões presentes no tecido social sobre a sexualidade na infância e adolescência e a desafiadora tarefa de pautar a saúde e os direitos sexuais como parte intrínseca dos direitos humanos desse grupo.

Nesse contexto, garantir os direitos sexuais e reprodutivos é participar do processo de transição do lugar histórico de crianças e adolescentes como objetos de tutela do Estado para o lugar de sujeitos de direitos, transição iniciada com a promulgação do ECA, no ano de 1990, e em plena vigência. A trajetória percorrida nesses 25 anos tem buscado afirmar, desde o ponto de vista legal e cultural, o entendimento da criança/adolescente como sujeito de direitos, permitindo-se aqui a proposição de desafios a fim de contribuir neste percurso: a construção de uma cultura que reconheça crianças e adolescentes também como sujeitos éticos. Portanto, não é apenas necessário garantir e avançar nos direitos sexuais e reprodutivos de crianças/adolescentes por ser direito, mas também e, sobretudo, por ser bom no sentido ético e necessário no sentido humano.

\section{Referências}

ASSIS, S. G.; SOUZA, E. R. Criando Caim e Abel: pensando a prevenção da infração juvenil. Ciência Et Saúde Coletiva, Rio de Janeiro, v. 4, n. 1, p. 131-144, 1999.

ÁVILA, M. B. Direitos sexuais e reprodutivos: desafios para as políticas de saúde. Cadernos de Saúde Pública, Rio de Janeiro, v. 19, supl. 2, p. 465-469, 2003.
BRASIL. Lei n ${ }^{\circ}$ 8.069, de 13 de julho de 1990. Dispõe sobre o Estatuto da Criança e do Adolescente e dá outras providências. Diário Oficial [da] União, Brasília, DF, 13 jul. 1990. Disponível em: <http://www.planalto.gov.br/ ccivil_03/LEIS/L8069.htm>. Acesso em: 26 nov. 2015.

Portaria Interministerial n. 1426 em 14 de julho de 2004. Aprova as diretrizes para a implantação e 
implementação da atenção à saúde dos adolescentes em conflito com a lei, em regime de internação e internação provisória, e dá outras providências. Diário Oficial da União, Brasília, DF, 14 jul. 2004a. Disponível em: <http:// dtr2001.saude.gov.br/sas/PORTARIAS/Port2004/GM/ GM-1426.htm>. Acesso em: 26 nov. 2015.

Portaria Interministerial n. 340/2004 de 07 de julho de 2004. [sem descrição]. Diário Oficial da União, Brasília, DF, 07 jul. 2004. 2004b. Disponível em: <http:// www.saude.mg.gov.br/index.php?option=com_gmg\&co ntroller=document\&id=830>. Acesso em: 26 nov. 2015.

Secretaria Especial dos Direitos Humanos. Conselho Nacional dos Direitos da Criança e do Adolescente. Sistema Nacional de Atendimento Socioeducativo: SINASE. Brasília, DF: Conanda, 2006.

Portaria Interministerial n. 647/2008, de 11 de novembro de 2008. [sem descrição]. Diário Oficial [da] União, Brasília, DF, 11 nov. 2008. Disponível em: <http:// www.saude.mg.gov.br/index.php?option=com_gmg\&co ntroller=document\&id=830 >. Acesso em: 26 nov. 2015.

Lei n. 12.594, de 18 de janeiro de 2012. Institui o Sistema Nacional de Atendimento Socioeducativo (Sinase), regulamenta a execução das medidas socioeducativas destinadas a adolescente que pratique ato infracional e dá outras providências. Presidência da República. Casa civil. Subchefia para assuntos jurídicos. Diário Oficial [da] União, Brasília, DF, 18 jan 2012a. Disponível em: <http://www2.camara.leg.br/legin/fed/ lei/2012/lei-12594-18-janeiro-2012-612303-publicacaooriginal-134972-pl.html>. Acesso em: 26 nov. 2015.

Conselho Nacional de Justiça. Panorama

Nacional. A execução das medidas socioeducativas de internação: programa justiça ao jovem. Brasília, DF, 2012b. Disponível em: <http://www.cnj.jus.br/images/ pesquisas-judiciarias/Publicacoes/panorama_nacional_doj_web.pdf>. Acesso em: 25 jan. 2013.

Ministério da Saúde. Portaria GM n. 1082, 23 de maio de 2014. Redefine as diretrizes da Política Nacional de Atenção Integral à Saúde de Adolescentes em Conflito com a Lei, em Regime de Internação e Internação Provisória (PNAISARI), incluindo-se o cumprimento de medida socioeducativa em meio aberto e fechado; e estabelece novos critérios e fluxos para adesão e operacionalização da atenção integral à saúde de adolescentes em situação de privação de liberdade, em unidades de internação, de internação provisória e de semiliberdade. Diário Oficial [da] União, Brasília, DF, 23 maio 2014a. Disponível em: <http://bvsms.saude. gov.br/bvs/saudelegis/gm/2014/prt1082_23_05_2014. html>. Acesso em: 26 nov. 2015.

Presidência da República. Secretaria dos Direitos Humanos. Levantamento Nacional dos e das adolescentes em conflito com a lei - 2012. Brasília, DF, 2014b. Disponível em: <http://www.sdh.gov.br/ assuntos/criancas-e-adolescentes/pdf/levantamento-sinase-2012>. Acesso em: 26 nov. 2015.

CAVALCANTE JUNIOR, I. G. O cuidado de si; por uma hermenêutica mais próxima do sujeito. 2008. Disponível em: <http://www.fap.com.br/fapciencia/002/edicao_2008/007.pdf >. Acesso em: 8 maio 2015.

DECLARAÇÃO e Plataforma de Ação da IV Conferência Mundial sobre a Mulher. Pequim, 1995. Disponível em: <http://www.spm.gov.br/Articulacao/ articulacao-internacional/relatorio-pequim.pdf $>$. Acesso em: 23 jul. 2013.

DELL'AGLIO, D. D. et al. Eventos estressores no desenvolvimento de meninas adolescentes cumprindo medidas sócio-educativas. Paidéia (Ribeirão Preto), Ribeirão Preto, v. 15, n. 30, p. 119-129, 2005.

FOUCAULT, M. A Hermenêutica do sujeito: curso dado no Collége de France (1981-1982). São Paulo: Martins Fontes, 2010.

História da sexualidade: a vontade de saber. Rio de Janeiro: Graal, 1988.

História da sexualidade: o uso dos prazeres. Rio de Janeiro: Graal, 1984

FRANÇA, S. A. M. A indisciplina como matéria de trabalho ético e político. In: AQUINO, J. G. (Org.). Indisciplina na escola; alternativas teóricas e práticas. São Paulo: Summus, 1996. p. 139-148. 
GIL, A. C. Métodos e técnicas de pesquisa social. 6. ed. São Paulo: Atlas, 1994.

KUHN, T. A estrutura das revoluções científicas. São Paulo: Perspectiva, 1989.

LOWENKRON, L. (Menor)idade e consentimento sexual em uma decisão do STF. Revista de Antropologia, São Paulo, v. 50, n. 2, p. 713-746, 2007.

MELO, E. R. Direito e norma no campo da sexualidade na infância e adolescência. In: UNGARETTI, M. A (Org.). Criança e adolescente: direitos, sexualidades e reprodução. São Paulo: ABMP, 2010. p. 43-60.

MINAYO, M. C. S. O desafio do conhecimento: pesquisa qualitativa em saúde. São Paulo: Hucitec, 1992.

NEVES, R.G. "Cuidado de si”, um princípio inspirador para o ensino da Filosofia junto a adolescentes. 2015. 167 f. Dissertação (Mestrado Profissional Adolescente em Conflito com a Lei) - Universidade Anhanguera de São Paulo, São Paulo, 2015.

PASCHE, D. F. et al. Rede Cegonha: desafios de mudanças culturais nas práticas obstétricas e neonatais.
Divulgação em Saúde para Debate, Rio de Janeiro, n. 52 , p. $58-71,2014$

PIROTTA, W. R. B.; PIROTTA, K. C. M. Relações de gênero e poder: os adolescentes e os direitos sexuais e reprodutivos no Estatuto da Criança e do Adolescente. In: ADORNO, R. C. F.; ALVARENGA, A. T.; COSTA, M. P. (Org.). Jovens, trajetórias, masculinidades e direitos. São Paulo: Fapesp: Editora da Universidade de São Paulo, 2005, p. 75-90.

UNITED Nations International Conference on Population and Development. Cairo, 1994. Disponível em: <www.iisd.ca/cairo.html>. Acesso em: 13 jun. 2012.

VENTURA, M. Sexualidade e reprodução na adolescência. In: ADORNO, R. C. F.; ALVARENGA, A. T.; COSTA, M. P. (Org.). Jovens, trajetórias, masculinidades e direitos. São Paulo: Fapesp: Editora da Universidade de São Paulo, 2005. p. 31-52.

VENTURA, M. et al. Direitos sexuais e direitos reprodutivos na perspectiva dos direitos humanos. Rio de Janeiro: Advocaci, 2003.

Recebido para publicação em maio de 2015

Versão final em julho de 2015

Conflito de interesses: inexistente

Suporte financeiro: não houve 